\title{
Consonant Repertoire of a Prelinguistically Deaf Child with Late-Mapping Cochlear Implants
}

Binos $\mathrm{P}^{1 *}$, Sfakianaki $\mathrm{A}^{2}$ and Psillas $\mathrm{G}^{3}$

${ }^{1}$ Department of Rehabilitation Sciences, Cyprus

University of Technology, Cyprus

${ }^{2}$ Speech Signal Processing Laboratory, Computer Science Department, University of Crete, Greece

${ }^{3} 1^{\text {st }}$ Academic ENT Department, Aristotle University of Thessaloniki, AHEPA Hospital, Greece

*Corresponding author: Binos P, Department of Rehabilitation Sciences, Cyprus University of Technology, Pavlou Mela 3, Nicosia 2051, Cyprus

Received: J une 12, 2021; Accepted: J uly 10, 2021; Published: J uly 17, 2021

\section{Abstract}

Objective: The present case study aims to report on the consonant repertoire during the pre-linguistic and first linguistic stage of a Greek-Cypriot speaking child bilaterally implanted with multichannel Cochlear Implants (Cls).

Background: Children with Hearing Loss $(\mathrm{HL})$ produce canonical babble later, and consonantal inventories of $\mathrm{HL}$ children are smaller. However, the consonant repertoire of $\mathrm{Cl}$ Greek-speaking children has not been examined thus far and research on types of consonantal errors during phonological acquisition is scant.

Clinical Case: A pre-linguistically deaf child ( $\mathrm{CY}, 7 ; 0$ years old) received the first $\mathrm{Cl}$ at 7 months of age, but the external part of the device was fitted at $2 ; 7$ years. An investigation of the child's speech at 7;0 years was conducted through auditory analysis. The child's canonical utterances were transcribed in IPA and his consonants were classified into subcategories, depending on articulation place, articulation manner and resonance. Regarding place, alveolar consonants were the main category produced. As regards manner, closed consonants was the first category to appear, while in terms of voicing, voiceless consonants were recorded more often than voiced ones. The analysis also showed that consonants $/ \mathrm{t} / \mathrm{/} / \mathrm{s} /$ and $/ \mathrm{p} /$ were dominant in the child's speech and revealed several phonological processes.

Conclusion: The present case holds special interest as the child's phonological system is still between the pre-linguistic/first linguistic stages due to the delayed $\mathrm{Cl}$ mapping. The results agree in part with several studies in the literature, while specific phonological error patterns observed, remain to be verified in other $\mathrm{Cl}$ Greek-speaking children.

Keywords: Consonants; Pre-linguistic speech; Cochlear implant

\section{Abbreviations}

CI: Cochlear Implant; CA: Chronological Age; PIA: Post Implant Age; IPA: International Phonetic Association; TD: Typically Developing Children

\section{Introduction}

Deaf children with CIs receive robust access to sound, but speech production skills exhibit great variability [1]. CIs trigger speech production skills, but the auditory signal is still degraded compared to normal hearing. Young children with CIs exhibit similar phonological acquisition as Typically Developing children (TD), but the investigation of consonant repertoire in Greek-speaking children with CIs has hardly been studied [2].

Normal hearing babies begin to babble at an average age of about 6 to 11 months [3]. Between 7 and 10 months, canonical babbling begins, where consonant-vowel syllables take a corresponding form to that of adults. According to the "infraphonological" model [4], during canonical babbling syllabic CV structures are characterized by a rapid transition $(<250 \mathrm{msec})$ from the consonant to the vowel, with a maximum duration of up to $500 \mathrm{msec}$. Children move from canonical to variegated babbling and the first words from six to twelve months of age [4].

During canonical babbling articulated movements are produced resulting in 100 to $500 \mathrm{msec}$ syllables with a frequency alternation lasting 25 to $120 \mathrm{msec}$ [3]. The syllables are produced with normal articulation and resonance [3]. Canonical babbling consists of either a syllable that meets these criteria or a rhythmic sequence of syllables, either repeated or differentiated [3]. In reduplicated babbling, the same syllable is repeated throughout the production. In variegated babbling, the syllabic structure is complex, consisting of consonants or vowels, or both. According to studies, reduplicated and variegated babbling occurs in two separate stages [6-8]. In these early developmental stages of speech, it is crucial to monitor performance and evaluate the effectiveness of CIs. Only little is known so far about the early acquisition of consonants in young CI children. Accurate production of consonants significantly promotes speech intelligibility, an area of major importance in rehabilitation of CI children.

Recently, language disorders in CI children were linked to poor consonant diversity [9], and consonant accuracy was related to better later vocabulary at 30 months and articulation at 36 months of age [10]. Despite the improved performance in accuracy and intelligibility 
of older CI children, their results remain poorer than their TD peers. The same stands for young CI children as well, especially when they are matched for chronological age. The aforementioned literature concerns research outcomes during the meaningful words and sentences stages but not during the canonical babbling period. Thus, studies during the pre-linguistic period could provide unique insight into the initial stages of consonant inventory and classification.

\section{Case Presentation}

The present report describes longitudinally the development of initial consonants in spontaneous speech vocalizations of a child (DY) with prelinguistic, profound $(>90 \mathrm{~dB} \mathrm{HL}$ ) bilateral, sensorineural hearing loss, aged $7 ; 0$ years at the beginning of the study. DY received the first CI at 7 months of age, but the external part of the device was fitted after 2 years, since the family had had no access to habilitation services. The boy received the second CI (left) at the age of 3;7 years. CY had unknown deafness etiology, no other disabilities, and he came from a monolingual Cypriot-Greek speaking Romani family of lower social-economic status. Cypriot Greek is a dialect of Greek spoken in Cyprus and has various phonological, syntactic and lexical differences from the standard variety [10]. The child received speech-language therapy for the first time when his Post-Implant Age (PIA) was 4;5 years and auditory/aural therapy when his PIA was 5;5 years. DY received a full orofacial examination without findings and his receptive vocabulary and morphosyntactic skills were evaluated through the Diagnostic Test of Verbal Intelligence (DVIQ) [12] and failed. TONI-4, a non-linguistic IQ test classified his performance as "average" (similar to 7;3 year old peers).

Protophones were transcribed and classified using the IPA from the canonical babbling to the first words stage on the basis of 13 recordings (using a Sony-PCM D50 digital recorder at $44.1 \mathrm{kHz}$ and 16bit) of 45 minutes each conducted during the period of 1 year (from 7;0 to $8 ; 0$ years old). The auditory analysis excluded prelinguistic sounds as primitive while canonical babbling productions were transcribed according to the IPA. These protophone categories constitute an infant's infraphonological repertoire [13]. Consonants were classified into subcategories according to place of articulation, manner of articulation and voicing (vocal fold vibration). Finally, reflexive and vegetative sounds were excluded from the analysis [14]

Consonant classification was based on 256 productions in total, transcribed in IPA. Overall, DY's spontaneous vocalizations were dominated by the sounds $/ \mathrm{t} /, \mathrm{s} /$ and $/ \mathrm{p} /$, while other consonantal sounds, such as $/ \delta /, / \mathrm{n} /, / \mathrm{z} /, / c ̧ /$ and $/ \mathrm{y} /$ appeared less frequently in his phonetic repertoire. As to place of articulation, 56\% were alveolars, and only $23 \%$ were bilabials. Other consonantal categories such as velars or palatal consonants reached only $10 \%$ and $5 \%$, respectively. Regarding manner of articulation, most of the sounds were plosives with $45 \%$, fricatives with $23 \%$, nasals with $21 \%$ and approximants only with 9\%. Lastly, concerning voicing, unvoiced consonants dominated the vocalization reaching $65 \%$ while voiced consonants were transcribed only in $35 \%$ of the cases.

During DY's spontaneous speech, many phonological processes were located. Specific errors included, among others, substitutions and deletions. In particular, weak syllable deletion (/ba'nana/ /'nana/), reduplication (/'pe $\mathrm{p}^{\mathrm{n}} \mathrm{de} / \mathrm{-} /$ 'pepe/) and initial consonant deletion (/'yata/ - /'ata/, /'milo/ - /'mio/, /'Sasos/ - /'Saso/) were evident in his speech. There was also assimilation (/ro'loi/ - /lo'loi/), fronting (/'kato/ - /'tato/) and alveolarization (/'Өema/ - /'sena/).

\section{Discussion}

The present case report aimed to analyze and classify the consonant repertoire during the pre-linguistic and first lexical stage of speech development of a child with $\mathrm{CI}$. The present findings agree with those of other studies $[15,16]$, which report that CI consonant repertoire is dominated by labials, alveolars and nasals; however, alveolar plosives outnumber other categories in the present study, in accordance with the "coronal preference" documented in previous literature [17]. As for voicing, voiceless consonants appear twice as often in comparison with voiced consonants. Although studies reporting CI consonant acquisition in other languages do not particularly focus on voiced vs voiceless consonant production rate, voiced consonants seem to appear more frequently in early inventories $[16,18]$. A voicing contrast study in consonant production of Greek-speaking CI children [19] showed longer duration of VOT in voiceless consonants and shorter duration of prevoicing in voiced consonants compared with those of TD counterparts. Hence, a next step in our analysis would entail accuracy measurements and acoustic descriptions of different consonantal categories. Lastly, similar phonological procedures with those reported in the present study have also been documented in CI research in other languages [20-22]. Regarding Greek, there is only one study comparing aspects of phonological acquisition of one child with CI with one child with hearing aids [23]. Our findings only partially agree as, for example, fronting and final consonant deletion were frequent in the present case study but did not occur in [23]. Differences in PIA and duration of speech-language therapy may account for variable findings.

As expounded in the literature, early implantation and appropriate rehabilitative support are critical factors so that speech development in CI children can follow that of TD peers [16]. The current investigation attempted to provide longitudinal data from a single case where these two factors were not met and enrich the knowledge-base regarding consonant repertoire development in CI recipients with small PIA exposed to the Cypriot-Greek language.

\section{References}

1. Niparko JK, Tobey EA, Thal DJ, Eisenberg LS, Wang N-Y, Quittner AL, et al. Spoken language development in children following cochlear implantation. JAMA: the Journal of the American Medical Association. 2010; 303: 14981506.

2. Spencer L \& Guo L. Consonant development in pediatric cochlear implant users who were implanted before 30 months of age. Journal of Deaf Studies and Deaf Education. 2012; 18: 93-109.

3. Rvachew S \& Alhaidary A. The phonetics of babbling: Oxford Research Encyclopedia of Linguistics. 2018.

4. Oller DK. The emergence of the speech capacity. Psychology Press. 2000.

5. Kent RD \& Bauer HR. Vocalizations of one-year-olds. Journal of Child Language. 1985; 12: 491-526.

6. Elbers L. Operating principles in repetitive babbling: A cognitive continuity approach. Cognition. 1982; 12: 45-63.

7. Oller DK. The emergence of the sounds of speech in infancy. In GH Yeni-Komshian \& JF Kavanagh \& CA Ferguson (Eds.), Child phonology: Production. 1980: 93-112.

8. Stark RE. Stages of speech development in the first year of life. In GH Yeni- 
Komshian, JF Kavanagh \& CA Ferguson (Eds.), Child phonology. 1980: 73 92.

9. Geers AE, Nicholas J, Tobey E, Davidson L. Persistent language delay versus late language emergence in children with early cochlear implantation. Journal of Speech, Language and Hearing Research. 2016; 59: 155-170.

10. Moeller MP, Hoover B, Putman C, Arbataitis K, Bohnenkamp G, Peterson $B$, et al. Vocalizations of infants with hearing loss compared with infants with normal hearing: Part II--transition to words. Ear Hear. 2007; 28: 628-642.

11. Mennen I, Okalidou A. Acquisition of Greek phonology: an overview. QMCU WP10. 2006

12. Stavrakaki S, Tsimpli M. Diagnostic verbal IQ test for Greek preschoo and school age children: standardization, statistical analysis, psychometric properties. In proceedings of the $8^{\text {th }}$ conference on speech therapy. 2000 95-106.

13. Buder EH, Warlaumont AS, Oller DK. An acoustic phonetic catalog of pre speech vocalizations from a developmental perspective. In B Peter \& A MacLeod (Eds.), Comprehensive perspectives on child speech development and disorders: Pathways from linguistic theory to clinical practice. Hauppauge NY: NOVA.

14. Binos P, Thodi C, Vogazianos P, Psillas G, Constantinidis J. An acoustic and auditory analysis of vocants in infants with cochlear implants. Logopedics Phoniatrics Vocology. 2021; 1: 28-34.

15. Bouchard ME, Normand MT \& Cohen H. Production of consonants by prelinguistically deaf children with cochlear implants. Clinical Linguistics \& Phonetics. 2007; 21: 875-884.
16. Sundarrajan M, Tobey EA, Nicholas J, Geers AE. Assessing consonant production in children with cochlear implants. J Com Disorders. 2020; 84: 105966.

17. Dillon C, Pisoni DB, Cleary M, Carter AK. Nonword imitation by children with cochlear implants: Consonant analyses. Arch Otolaryngol Head Neck Surg. 2004; 130: 587-591.

18. Lin Y-S, Peng S-C. Acquisition Profiles of Syllable-initial Consonants in Mandarin-speaking Children with Cochlear Implants. Acta Oto-Laryngologica. 2003; 123: 1046-1053.

19. Koupka GA, Okalidou A, Nicolaidis K, Konstantinidis I, Kyriafinis G. Production of the voicing contrast by Greek children with cochlear implants. Proc. $3^{\text {rd }}$ Int Conf. Natural Lang \& Speech Proccesing. 2019; 114-119.

20. Faes J \& Gillis S. Consonant cluster production in children with cochlear implants: A comparison with normally hearing peers. First language. 2017; 37: 319-349.

21. Adi-Bensaid L \& Ben-David A. Typical acquisition by atypical children: Initia consonant cluster acquisition by Israeli Hebrew-acquiring children with cochlear implants. Clinical Linguistics \& Phonetics. 2010; 24: 771-794.

22. Baudonck N, Dhooge I, D'haeseleer E, Van Lierde K. A comparison of the consonant production between Dutch children using cochlear implants and children using hearing aids. Int J Ped. Otorhinolaryngol. 2010; 74: 416-421.

23. Lazarou E, Hatzopoulou M. The effect of cochlear implants on phonological acquisition. Ex-Ling. 2010: 89-92. 